\title{
Erratum: Probes: FRET sensor design and optimization
}

\section{Vivien Marx}

Nat. Methods 14, 949-953 (2017); published online 29 September 2017; corrected after print 13 October 2017

In the version of this article initially published, the captions and image credit information for images from the Frommer lab and the Lin lab were swapped. The image from the Frommer lab was also truncated. The errors have been corrected in the PDF and HTML versions of this article.

\section{Corrigendum: Accurate identification of single-nucleotide variants in whole-genome-amplified single cells}

Xiao Dong, Lei Zhang, Brandon Milholland, Moonsook Lee, Alexander Y Maslov, Tao Wang \& Jan Vijg

Nat. Methods 14, 491-493 (2017); published online 20 March 2017; corrected after print 13 October 2017

In the version of this article initially published, Lodato, M.A. et al. Science 350, 94-98 (2015) (reference 2) was cited as an example of a single-cell sequencing study with high CG-to-TA transitions that applies heat lysis. However, that work used alkaline lysis on ice (Walsh, C.A. and Lodato, M.A., personal communication); therefore, we have changed the third sentence of the paper from "This pathway may

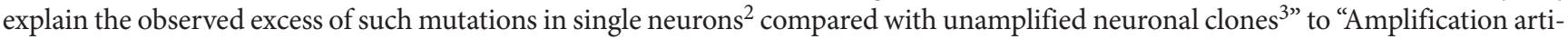
facts could, in general, explain the observed excess of such mutations in single neurons ${ }^{2}$ compared with unamplified DNA from neuronal clones." The error has been corrected in the HTML and PDF versions of the article. 